\title{
Frequency and Sensitivity Pattern of Neisseria gonorrhoae Isolated from Women at a Tertiary Care Hospital in Dhaka City
}

\author{
Fatema Nusrat $^{1}$, K.M. Shahidul Islam ${ }^{2}$, S.M. Shamsuzzaman ${ }^{3}$, Md. Abdullah Yusuf $^{4}$, Aleya Farzana ${ }^{5}$, \\ Samia Afrin ${ }^{6}$ \\ ${ }^{1}$ Lecturer, Department of Microbiology, Shaheed Suhrawardy Medical College, Dhaka, Bangladesh; ${ }^{2}$ Professor \& Head, Department of \\ Microbiology, Dhaka Medical College, Dhaka, Bangladesh; ${ }^{3}$ Professor, Department of Microbiology, Dhaka Medical College, Dhaka, \\ Bangladesh; ${ }^{4}$ Assistant Professor, Department of Microbiology, National Institution of Neurosciences \& Hospital, Dhaka, Bangladesh; \\ ${ }^{5}$ Lecturer, Department of Microbiology, Sir Salimullah Medical College, Mitford, Dhaka, Bangladesh; ${ }^{6}$ Assistant Professor, Department \\ of Microbiology, ZH Sikder Women's Medical College, Dhaka, Bangladesh
}

[Received: 20 January 2014; Accepted: 15 May 2014; Published: 1 June 2014]

\begin{abstract}
Background: Antibiotic sensitivity pattern of Neisseria gonorrhoae is changing frequently. Objective: The purpose of the present study was to see the antibiotic sensitivity pattern of Neisseria gonorrhoae isolated from women presented with cervicitis. Methodology: This cross sectional study.carried out in the Department of Microbiology at Dhaka Medical College, Dhaka from July 2011 to December 2012 for a period of one and half year. All the women presented with or without the clinical features of cervicitis at child bearing age (15 to $49 \mathrm{yrs}$ ) with or without pregnancy were enrolled as study population. Endocervical swabs were collected for Gram staining, culture, biochemical test from clinically diagnosed patients of cervicitis for presumptive identification of Neisseria gonorrhoeae. The isolates with presumptive identification were confirmed by rapid carbohydrate utilization test (RCUT), which differentiates N.gonorrhoeae from other Neisseria. Antimicrobial susceptibility test was done according CLSI guideline. Result: A total 245 females were recruited of which $N$. gonorrhoeae were detected from 39(15.9\%) cases. Among 39 positive cases of gonococcal cervicitis, 19 (48.71\%) were detected in the age group of $21-30$ years. $56.41 \%$ were sensitive and $30.76 \%$ were resistant to ceftriaxone. Similarly $51.28 \%$ were sensitive and $23.07 \%$ were resistant to cefuroxime; $23.07 \%$ sensitive, $30.76 \%$ moderately sensitive and $46.15 \%$ resistant to ciprofloxacin. Conclusion: Gonococcal cervicitis is found in a high frequency rate with a reduced sensitivity to antibiotics especially ciprofloxacin, second and third generation cephalosporins. [Bangladesh J Infect Dis 2014;1(1):3-7]
\end{abstract}

Keywords: Sensitivity pattern; Neisseria gonorrhoae; cervicitis

[How to Cite this article: Nusrat F, Islam KMS, Shamsuzzaman SM, Yusuf MA, Farzana A, Afrin S Frequency and Sensitivity Pattern of Neisseria gonorrhoae Isolated from Women at a Tertiary Care Hospital in Dhaka City. Bangladesh J Infect Dis 2014;1(1):3-7]

Corresponding author: Dr. Fatema Nusrat, Lecturer, Department of Microbiology, Shaheed Suhrawardy Medical College, Sher-E-Bangla Nagar, Dhaka-1207, Bangladesh; Email: drfnusrat@gmail.com; Cell no.: $+8801711319581$

Conflict of Interest: Authors have declared no conflict of interest.

Contributions to authors: FN, KMSI, SMS have contributed from protocol preparation to manuscript writing as well as in data collection. MAY, AF \& SA have prepared and revised the manuscript as well as data analysis. 


\section{Introduction}

Cervicitis is more common in the women of childbearing age that is between 15 to 49 years ${ }^{1}$. Neisseria gonorrhoeae and Chlamydia trachomatis account for about half of the cervicitis cases ${ }^{2}$. Among these two diseases, gonococcal infection is one of the oldest known bacterial diseases ${ }^{3}$; however, it still causes a significant morbidity among the sexually active individuals ${ }^{4}$. In Bangladesh, the prevalence of gonococcal cervicitis is $0.2 \%$ to $0.5 \% \%^{5}$. Gonococcal cervicitis can be diagnosed by detecting gram negative intracellular diplococcic in cervical exudates but it's sensitivity is $<55 \%{ }^{6}$. Culture has a sensitivity of 85 to $95 \%$ but it needs special care as $N$. gonorrhoeae is a fastidious organism and very much susceptible to drying ${ }^{7}$. Although culture has advantage to observe the antibiotic susceptibility of the isolated bacteria, it needs selective media and at least 3 days period is needed to provide a positive result ${ }^{7-8}$. Antimicrobial resistance in $N$. gonorrhoeae is the most significant challenge to control gonorrhea. Gonococcal strains are resistant to penicillins, tetracyclines and recently resistant strains to fluroquinolones and azithrtomycin have emerged ${ }^{9}$. Ceftriaxone retains its activity but recently isolates are detected with decreased sensitivity in various regions of the world ${ }^{10}$.

In Bangladesh, the non-selective culture methods are being used in the laboratory practices for isolation of Neisseria gonorrhoeae, the sensitivity of which is very low. So, the usage of selective media can make better isolation of the organism. Few studies have been carried out in Bangladesh regarding diagnosis of bacterial causes of cervicitis including Neisseria gonorrhoeae $e^{5,11}$. Therefore, the study is designed to isolate and identify Neisseria gonorrhoeae from endocervical swab specimens of suspected patients of cervicitis attending Dhaka Medical College Hospital by culture.

\section{Methodology}

This was a cross sectional study.carried out in the Department of Microbiology at Dhaka Medical College, Dhaka from July 2011 to December 2012 for a period of one and half year. All the women presented with or without the clinical features of cervicitis at child bearing age ( 15 to $49 \mathrm{yrs}$ ) with or without pregnancy who were attended at Gynaecology and Obstetrics out patient department (OPD) of Dhaka Medical College Hospital were enrolled as study population. Women with per vaginal bleeding or menopause women or receiving any antimicrobial drugs in the past 15 days were excluded from this study. It was approved by the research review committee (RRC) and ethical review committee of Dhaka Medical College. Informed written consent was taken from each patient before sample collection. Three endocervical swabs were collected from clinically diagnosed patients of cervicitis $^{12}$. One swab was immediately used for Gram staining. Another swab was used for culture and the third one was mixed with $2 \mathrm{ml}$ sterile phosphate buffer saline and kept at $-20^{\circ} \mathrm{C}$ until it was used for $\mathrm{PCR}^{13}$. In Gram stained smear, pus cells were observed and Neisseria gonorrhoeae was identified by presence of intracellular and extracellular bean shaped gram negative diplococci. The specimen of endocervical swab was inoculated on blood agar, chocolate agar and Modified Thayer Martin (MTM) media with proper labeling. The inoculated plates were then kept into $\mathrm{CO}_{2}$ extinction jar with soaked paper towel at the bottom and the lid of the jar was closed tightly. Each time the jar was opened to keep a new inoculated plate, the candle was flamed. The $\mathrm{CO}_{2}$ jar was kept at $37^{\circ} \mathrm{C}$ for over night incubation. Culture plates were examined after 24 hours of incubation for growth of Neisseria gonorrhoeae. N. gonorrhoeae was grown both in chocolate agar and selective Modified Thayer Martin media. Presumptive identification of Neisseria gonorrhoeae was done by colony morphology, oxidase test, superoxol test and Gram staining and species identification was done by carbohydrate utilization test and PCR. The isolates with presumptive identification were confirmed by rapid carbohydrate utilization test (RCUT), which differentiates N.gonorrhoeae from other Neisseria. Finally $N$. gonorrhoeae was confirmed by detecting DNA of $N$. gonorrhoeae by PCR using species specific primers. Antimicrobial susceptibility test was done for all N.gonorrhoeae isolates with five antimicrobial agents such as penicillin (10unit), tetracycline $(30 \mu \mathrm{g})$, ceftriaxone $(30 \mu \mathrm{g})$, ciprofloxacin $(5 \mu \mathrm{g})$ and cefuroxime $(30 \mu \mathrm{g})$ following CLSI guideline ${ }^{14}$. The susceptibility was done by disc diffusion method to find out inhibitory zone diameters to the discs of recommended strength following CLSI guideline ${ }^{14}$. The plates were then incubated in a humid atmosphere with $510 \% \mathrm{CO}_{2}$ inside a candle jar at $37^{\circ} \mathrm{C}$ for 24 hours. A representative of each batch of discs was tested with WHO reference strains of N. gonorrhoeae ATCC 49226 and Staphylococcus aureus ATCC 25923 to verify their optimum performance before disc diffusion test was done with the clinical isolates. After 18 to 24 hours of incubation each plate was examined and the diameter of each zone of inhibition was measured with a scale $^{12}$. Statistical analysis was performed by SPSS 19. The qualitative data were expressed as frequency and percentage and the quantitative data were expressed as mean and standard deviation. 


\section{Result}

A total 245 females of child bearing age (15 $49 \mathrm{yrs}$ ), both pregnant and non pregnant were recruited after fulfiling the inclusion and exclusion criteria of which N. gonorrhoeae were detected from 39(15.9\%) cases.

Table 1: Rate of Isolation of $N$. gonorrhoeae among Study Population $(n=245)$

\begin{tabular}{lcc}
\hline N.gonorrhoeae & Frequency & Percentage \\
& & \\
\hline Positive & 39 & 15.9 \\
Negative & 206 & 84.1 \\
Total & $\mathbf{2 4 5}$ & $\mathbf{1 0 0 . 0}$ \\
\hline
\end{tabular}

Among 39 positive cases of gonococcal cervicitis, 19 $(48.71 \%)$ were detected in the age group of $21-30$ years followed by $10(25.64 \%)$ in $31-40$ years. Only 3 $(7.70 \%)$ cases were found in $15-20$ years of age group.

Table 2: Distribution of Study Population According to age $(\mathbf{n}=\mathbf{2 4 5})$

\begin{tabular}{lccc}
\hline $\begin{array}{l}\text { Age Group } \\
\text { (Years) }\end{array}$ & \multicolumn{2}{c}{$\boldsymbol{N}$. gonorrhoeae } & Total \\
\cline { 2 - 3 } & Positive & Negative & \\
\hline 15 to 20 & 3 & 17 & 20 \\
21 to 30 & 18 & 108 & 126 \\
31 to 40 & 8 & 56 & 64 \\
41 to 49 & 6 & 29 & 35 \\
Total & $\mathbf{3 9}$ & $\mathbf{2 0 6}$ & $\mathbf{2 4 5}$ \\
\hline
\end{tabular}

$*$ Mean $\pm \mathrm{SD}=29.4 \pm 8.45 ; \mathrm{p}$ value $=0.938$

Regarding antibiotic susceptiblty pattern of $N$. gonorrhoeae, $56.41 \%$ were sensitive and $30.76 \%$ were resistant to ceftriaxone. Similarly $51.28 \%$ were sensitive and $23.07 \%$ were resistant to cefuroxime; $23.07 \%$ sensitive, $30.76 \%$ moderately sensitive and $46.15 \%$ resistant to ciprofloxacin. The organism was $28.20 \%$ sensitive, $46.15 \%$ moderately sensitive and $25.64 \%$ resistant to penicillin; $38.46 \%$ sensitive and $35.89 \%$ resistant to tetracycline (Figure I).

\section{Discussion}

The causative organism of cervicitis are related to sexually transmitted infections ${ }^{15}$ which continues to present major health, social and economic problems in the developing world, leading to considerable morbidity, mortality and stigma ${ }^{16}$. The prevalence rates apparently are far higher in developing countries where STI treatment is less accessible ${ }^{15}$. An estimated 448 million new cases of curable STIs occur each year ${ }^{14}$ and the incidence was about 70.80 million in South-East Asian region ${ }^{17}$.

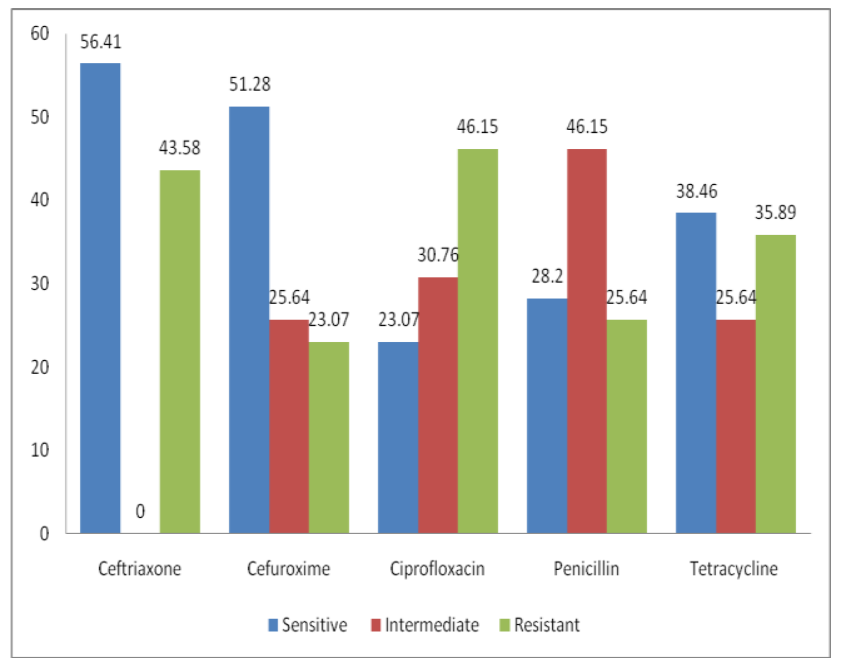

Figure 1: Antibiotic susceptibility pattern of $N$. gonorrhoeae

Gonococcal infection is one of the oldest diseases of the world that causes cervicitis in women ${ }^{18}$. About $30-50 \%$ of women have gonococcal infection ${ }^{19}$. In this study, among 245 suspected cases of cervicitis, $15.91 \%$ were positive for gonococcal infection and among them, $19(48.71 \%)$ were detected in the age group of 21-30 years. The mean age with SD of gonococcal infection was $29.4 \pm 8.45$ years. Desai et $\mathrm{al}^{20}$ observed the mean age of gonococcal. Chowdhury et $\mathrm{al}^{21}$ showed that $60 \%$ of sexually transmitted diseases were in the age group of 20-30 years which were in accordance with the study. Young women were particularly susceptible to STIs because they had fewer antibodies to fight pathogens and greater cervical ectopy ${ }^{19}$. The biologic basis for this association is thought to be anatomic differences in cervix of younger women and cervical change during puberty ${ }^{22}$.

In the present study, regarding antibiotic susceptiblty pattern of $N$. gonorrhoeae, $56.41 \%$ were sensitive, and $43.58 \%$ were resistant to ceftriaxone. In contrast to the present study, Olsen et $\mathrm{al}^{23}$ showed that $95 \% \mathrm{~N}$. gonorrhoeae were sensitive to this drug and $5 \%$ were resistant. However, Bala et $\mathrm{al}^{24}$ summarized some results and showed that less susceptible strains of $N$. gonorrhoeae to ceftriaxone emerged in some countries. Therefore, currently only ceftriaxone is not the drug of choice for treatment of gonococcal infection. In this study, among the isolates of $N$. gonorrhoeae, $23.07 \%$ were sensitive, $30.76 \%$ were moderately sensitive and $46.15 \%$ were resistant to ciprofloxacin. Shirin et $\mathrm{al}^{25}$ observed that $48.9 \% \mathrm{~N}$. gonorrhoeae were resistant to ciprofloxacin which is in accordance with the present study. In contrast, 
90.5\% resistance to ciprofloxacin was observed in 2002 by ICDDR, $\mathrm{B}^{26}$. Singh et $\mathrm{al}^{27}$ and Malar et $\mathrm{al}^{28}$ reported that $>70 \%$ of isolated $N$. gonorrhoeae were resistant to ciprofloxacin in India and South Asian countries. This emergence of resistance was probably the consequence of multiple factors, which include syndromic treatment of STDs particularly gonorrhea by ciprofloxacin, self medication by the patients, over use of this drug by clinicians in various other clinical conditions that might coexist with gonococcal infection. In this study, among the isolates of $N$. gonorrhoeae, $74.3 \%$ were susceptible and $25.6 \%$ were resistant to penicillin. Of them, $28.2 \%$ of $N$. gonorrhoeae were sensitive and $46.1 \%$ were moderately sensitive. Bala and $\operatorname{Sood}^{29}$ observed that $42.9 \%$ N. gonorrhoeae showed reduced susceptibility to penicillin and $\mathrm{Malar}^{28}$ showed that $29.6 \% \mathrm{~N}$. gonorrhoeae were resistant to this drug which is in accordance with the present study. On the other hand, Putnam et $\mathrm{al}^{30}$ showed in a study in South East Asia that $26.6 \% N$. gonorrhoeae were moderately sensitive and $60.6 \%$ were resistant to penicillin. A decade later, Singh et $\mathrm{al}^{27}$ reported $39.7 \% \mathrm{~N}$. gonorrhoeae were resistant to penicillin. So it is shown that the resistance to penicillin did not rise significantly over the last few years and the susceptibility of penicillin is increasing. This might be due to limited use of penicillin to treat gonorrhea cases in the recent years.

\section{Conclusion}

Gonococcal cervicitis is found in a high frequency rate with a reduced sensitivity to antibiotics especially ciprofloxacin, second and third generation cephalosporins. Therefore, clinician should aware of prescribing the antibiotics to the patients presented with gonococcus.

\section{References}

1. Mahmood MA, Saniotis A. Use of syndromic management algorithm for sexually transmitted infections and reproductive tract infections management in community settings in Karachi. J Pakistan Med Assoc 2011; 61 : 453

2. Nyirjesy P. Non-gonococcal and nonchlamydial cervicitis. Curr Infect Dis Rep, 2001; 3: 540-45

3. Wong B. Gonorrhoea. Medscape references. Updated at 20 February, 2013. Viewed on: 20 Decemebr 2013; Available at http://www.medscape.org/education. Accessed on March 2, 2013

4. Marazzo JM, Martin D. Management of women with cervicitis. Clin Infect Dis 2007; 44(3):102-10

5. Rahman S, Khan AI, Razzaq R, Shams I. Operational Aspects of Syndromic Management of RTIs/STIs at a Primary Healthcare-level Clinic. In: Khan MSI, ed. ICDDR,B Working Paper No.151.Bangladesg : ICDDR,B : Centre for Health and Population Research Inc; 2001:pp.20

6. World Health Organization.Bignell C, Unemo M. European (IUST/WHO) Guideline on the Diagnosis and Treatment of Gonorrhoea in Adults. In: Jensen JS , Radcliff K, Janier M, Moi H, Newmann M, Patel $\mathrm{R}$ et al.eds. Copenhagen, Denmark: World Health Organization, 2012
7. Alam A, Miah MR, Rahman M, Sattar H, Saleh AA. Comparison of PCR method with the culture method for identification of gonococci from endocervical swab. Indian $\mathrm{J}$ Med Microbiol, 2002; 20: 37-9

8. Lai-King $\mathrm{Ng}$, Martin IE. The laboratory diagnosis of Neisseria gonorrhoeae. Can J Infect Dis Med Microbiol, 2005; 16(1): 15-25.

9. Center for Disease Control and Prevention (CDC). Sexually transmitted diseases treatment guidelines, 2010. Morb Mortal Wkly Rep, 2010; 59 pp. 43-51.

10. Chisholm SA, Dave J, Ison CA. High level azithromycin resistance occurs in Neisseria gonorrhoeae as a result of a single point mutation in the 23s rRNA genes. Antimicrob Agents Chemother 2010; 54 (9) : 3812-16.

11. Bogaerts J, Ahmed J, Akhter N, Begum N, Rahman M, Nahar S et al. Sexually transmitted infections among married women in Dhaka, Bangladesh: unexpected high prevalence of herpes simplex type 2 infection. Sex Transm Infect, 2001; 77: $114-19$

12. Chessbrough M. Microbiological tests, Examination of urogenital specimens. In: Chessbrough M, eds. District laboratory practice in tropical countries. UK: Cambridge University press; 2009a : pp.142-43.

13. Hashemi FB, Pourakbari B, Yazdi JZ. Frequency of Chlamydia trachomatis in women with cervicitis in Tehran, Iran. Infect Dis Obstet Gynecol, 2007; 2007: 67014

14. Clinical and Laboratory Standards Institute (2013) Performance standards for antimicrobial susceptibility testing. 23rd Informational Supplement Document M100S23, CLSI, Wayne

15. Chin J. Public health surveillance of AIDS and HIV infections. Bull World Health Organ, 1990; 68: 529-36

16. Janda WJ, Knapp JS. Neisseria and Moraxella catarrhalis In: Murray PR, Baron EJ, Pfaller MA, Jorgensen JH, Yolken RH, eds. Manual of Clinical Microbiology, 8th edn. Washington, USA: American Society Microbiol 2003:585608

17. World Health Organization. Global prevalence and incidence of selected curable sexually transmitted disease : overview and estimates Geneva. WHO, 2001. Updated on: 10 January 2012; Viewed on: 15 September 2013; [Available at: http://www.who.int/reproductivehealth/publications/rtis/HIV _AIDS_2001_2/en/index.html]

18. Farley TA, Cohen DA, Elkins W. Asymptomatic sexually transmitted diseases: the case for screening. Prev Med 2003; 36:502-9.

19. Prasad JH, Abraham S, Kurz KM, George V, Lalitha MK, John $\mathrm{R}$ et al. Reproductive tract infections among young married women in Tamilnadu, India. International Family Planning Perspectives, 2005; 31(2): 73-82.

20. Desai VK, Kosambiya JK, Thakur HG, Umrigar DD, Khandwala BR, Bhuyan KK. Prevalence of sexually transmitted infections and perfprmance of STI syndromes against aetiological diagnosis, in female sex workers of red light area in Surat, India. Sex Transm Infect 2003; 79 : 11115

21. Chowdhury S, Ramachandran VG, Das S, Bhattacharya SN, Mogha NS. Pattern of sexually transmitted infections and performance of syndromic management against etiological diagnosis in patients attending the sexually transmitted infection clinic of a tertiary care hospital. Indian J Sex Transm Dis 2010; 31:104-8

22. Black CM. Current methods of laboratory diagnosis Chlamydia trachomatis infections. Clin Microbiol Rev,1997; 10(1): 160-84

23. Olsen B, Lan PT, Golparian D, Johansson E, Khang TH, Unemo M. Antimicrobial susceptibility and genetic characteristics of Neisseria gonorrhoeae isolates from Vietnam, 2011. BMC Infect Dis 2013; 13:40 
24. Bala M, Ray K, Gupta SM, Muralidhar S, Jain RK. Changing trends of antimicrobial susceptibility patterns of Neisseria gonorrhoeae in India and the emergence of ceftriaxone less susceptible $N$. gonorrhoeae strains. J Antimicob Chemother 2007; 60 (3) : 582-86

25. Shirin T, Rahman S, Rabbi FJ, Kabir MH, Mamun KJ. Prevalence of sexually transmitted diseases and transmission of HIV in Dhaka, Bangladesh. Bangladesh J Med Microbiol 2009; 3(1): 27-33

26. International center for diarrhoeal disease research, Bangladesh (ICDDR,B). Epidemiology og gonorrhoea and antimicrobial susceptibility surveillance for Neisseria gonorrhoeae in Bangladesh. Health Science Bulletin 2003; 1(2): 6-10

27. Singh V, Bala M, Kakran M, Ramesh V. Comparative assessment of CDS, CLSI disc diffusion and Etest techniques for antimicrobial susceptibility testing of Neisseria gonorrhoeae: a 6-yr study. BMJ Open 2012; 2(4): e000969

28. Malar ASS, Viswanathan T, Malarvizhi A, Lavanya V, Moorthy K. Prevalence and antimicrobial susceptibility pattern of Neisseria gonorrhoeae from rural area of Namakkal, Tamilnadu, India. Int J Interdisci Res Revs 2013;1(2):92-98

29. Bala M, Sood S. Cephalosporin resistance in Neisseria gonorrhoeae. J Global Infect Dis 2010;2:284-90

30. Putnam SD, Lavin BS, Stone JR, Oldfield III EC, Hopper DG. Evaluation of the standardized disk diffusion and agar dilution antibiotic susceptibility test methods by using strains of Neisseria gonorrhoeae from the United States and South East Asia. J Clin Microbiol 1992; 30 : 974-80 